\title{
Comportamentos de Ajuda no Contexto Urbano: Um Estudo Experimental por Meio do Telefone ${ }^{1}$
}

\author{
Abelardo Vinagre da Silva e Hartmut Günther ${ }^{2}$ \\ Universidade de Brasília
}

RESUMO - Utilitarismo e frieza nas relações pessoais entre habitantes de grandes cidades encontram respaldo em estudos norte-americanos. No Brasil, pouco se sabe sobre este tema. O uso do telefone como instrumento de pesquisa social experimental também não é freqüente em nossa cultura. Procurou-se verificar o nível de ajuda em função do tipo de residência (casa vs. apartamento), localização (centro vs. periferia) e gênero de quem pedia ajuda. Utilizando-se o procedimento do 'Número Errado' solicitou-se ajuda por telefone a 320 moradores de duas áreas urbanas. De modo geral, 39,3\% das pessoas contatadas ajudaram da maneira solicitada. Tipo de residência e localização não influenciaram a taxa de ajuda, mas mulheres receberam significativamente mais ajuda que os homens. A utilização do telefone como instrumento de pesquisa social mostrou-se possível. Para seu uso experimental discutiram-se alguns cuidados metodológicos.

Palavras-chave: comportamento pró-social; ajuda; telefone; área urbana.

\section{Helping Behavior in an Urban Setting: An Experimental Study Using the Telephone}

\begin{abstract}
Cold and calculating interpersonal relations among residents of large cities are described in North American studies. Little is known, however, about this topic in Brazil. The use of the telephone as a research instrument in social experiments also is not common in Brazilian's culture. An attempt was made to verify helping behavior as a function of type of home (house vs. apartment), local (center vs. periphery) and gender of the person seeking help. Using the 'wrong number technique', help was solicited by phone from 320 residents in two urban areas. Overall, 39,3\% of the persons contacted provided help. Type of home and local did not influence the rate of helping. However, female callers elicited more helping behavior than did male callers. The use the telephone as an instrument in social research proved possible. Several methodological aspects needing special attention in experimental use were also discussed.
\end{abstract}

Key words: pro-social behavior; help; telephone; urban area.

Qual o impacto da vida urbana sobre o comportamento social das pessoas? Desde as grandes migrações para o meio urbano esta pergunta estimula tanto as artes quanto as ciências sociais. A imagem popular - para não dizê-la romântica - é de que a vida nas cidades pequenas e no meio rural é amigável, humana e cooperativa. Nas cidades grandes isto não acontece mais. No artigo clássico de Milgram (1970) sobre a vida em cidades, uma cena de pessoas batalhando por um táxi na frente de uma estação ferroviária reflete um problema das cidades grandes. No Dia do Vizinho (20 de agosto), o Correio Braziliense, procurando mostrar as modificações nas relações entre pessoas, iniciou assim um artigo sobre vizinhos:

Houve um tempo, no interior, em que as relações entre vizinhos eram à base do ovo e tomate. Trocava-se, além da conversa, o recheio do bolo. ... Bons tempos aqueles!

1 Este estudo contou com o apoio do CNPq. Dados parciais deste estudo foram apresentados na XXVI Reunião Anual de Psicologia, Ribeirão Preto. Agradecemos a colaboração de Isabel Vinagre da Silva na coleta de dados.

2 Endereço: Caixa Postal 4480; 70919-970 Brasília - DF. E-mail: hartmut@unb.br
Na cidade grande, os prédios, o corre-corre diário e o desencontro das pessoas dificultam as relações, e cenas como essas são absolutamente inimagináveis. (Abreu, 1997)

A influência das grandes cidades sobre o comportamento não é facilmente identificada. A título de duas posições opostas, Wirth (1938) afirma que todos os aspectos de uma interação social são diferentes em uma área urbana, em decorrência de densidade, área e heterogeneidade da população. Gans, por outro lado, afirma que viver nas grandes cidades não tem impacto na vida social das pessoas, vez que o caráter das interações sociais é influenciado por fatores sociológicos (e.g., idade, classe sócio-econômica, etnia) que fazem parte da identidade individual, independentemente de condições externas da vida urbana (Gans, 1962; 1967, apud Korte, 1980). Milgram (1970) demonstrou que adaptações comportamentais à vida nas cidades podem ser medidas como outros comportamentos humanos e que certas formas de comportamento social podem ser vistas como adaptação aos - excessivos - níveis de "input social e ambiental" das grandes cidades. De maneira semelhante, Fischer (1975) acredita que morar na cidade afeta o comportamento social, mas sua ênfase recai sobre os aspectos subculturais (étnico, ocupacional ou religioso) da população urbana. Devido ao próprio tamanho da população urbana, é muito mais fácil que determinadas subculturas floresçam nas áreas urbanas, 


\section{A. V. Silva e H. Günther}

aumentando a probabilidade de ocorrerem comportamentos vistos como desvios ou como inovadores de padrões gerais, contribuindo para uma difusão de novas atitudes e comportamentos.

Em uma análise psicossocial do impacto da vida urbana, Korte (1980) sugere que a posição de Milgram e de Fischer tem encontrado mais respaldo em estudos sobre habitantes de centros urbanos, indicando, entre outros resultados, que deficiências no senso de responsabilidade social podem ser verificadas entre moradores de diferentes cidades. O caso Genovese é o exemplo clássico de uma situação que difícilmente ocorreria em um ambiente não urbano ou em uma pequena cidade:

Catherine Genovese, voltando para casa após uma noite de trabalho ...foi apunhalada repetidamente durante um prolongado período de tempo. Trinta e oito residentes de uma respeitável vizinhança da cidade de Nova York admitiram ter testemunhado pelo menos parte do ataque, mas ninguém foi em seu socorro... (Milgram, 1970, p. 1462)

Esse evento de 1964 estimulou uma série de estudos sobre o bystander ${ }^{2}$ (veja Cunningham, 1984; Eisenberg, 1991; Latané \& Darley, 1970; Steblay, 1987, para resenhas desta literatura). Pesquisadores fora do Brasil analisaram a influência de variáveis ambientais e sócio-contextuais sobre a probabilidade de oferecer / receber ajuda. Diferentes métodos experimentais e quase-experimentais, envolvendo inclusive cartas, telefone ou mesmo situações cotidianas foram utilizados nos estudos. Foram consideradas variáveis antecedentes: contato visual (Simon, 1971), densidade e área populacional (Amato, 1983a; Darley \& Latané, 1968; Hedge \& Yousif; 1992; Kammann, Thomson \& Irwin, 1979; Lerner, Solomon \& Brody, 1971; Mishra \& Das, 1983), área rural vs. urbana (Amato, 1983a, 1983b; Krupat \& Coury, 1975, apud Hedge \& Yousif, 1992), local de residência urbana e vizinhança (House \& Wolf, 1978; West, Whitney \& Shnedler, 1975), afiliação (Amato, 1983c; Shaffer \& Grazziano, 1980), idade (Amato, 1983c; Wunderlich \& Willis, 1977), gênero (Eagly \& Crowley, 1986; Howard \& Crano, 1974; Lay, Allen \& Kassirer, 1974; Rotton, 1977), etnia (Franklin, 1974;Gaertner \& Bickman, 1971; Harris \& Klingbeil, 1976), status social (Goodman \& Gareis; 1993; Solomon, Solomon \& Maiorca, 1982), status enquanto roupa (Mallozzi, McDermott \& Kay son, 1990) e características da situação de emergência (Clark \& Word, 1974).

Um dos problemas encontrados ao estudar comportamento de ajuda de maneira sistemática, seja em forma de experimento, seja por meio de questionário / entrevista, refere-se à reatância frente à situação de pesquisa. Sendo prestar ajuda um comportamento moral e socialmente correto, dificilmente alguém admitiria que não prestaria ajuda quando soubesse estar participando de uma pesquisa sobre essa temática. A alternativa é criar situações em que a disposição de ajudar pode ser estudada de maneira não reativa ${ }^{4}$. Entre as muitas

3 Pessoa que se encontra perto; espectador; curioso. técnicas da pesquisa de psicologia social, a de "número errado" tem uma considerável tradição, especialmente para estudar comportamento de ajuda (e.g., Boise \& Goldman, 1981; Goldman, Broll \& Carrill, 1983; Shaw, Borough \& Fink, 1994; Simon, 1971). O esquema básico é simples. Ligase para números selecionados de maneira randômica. Ao atenderem, conta-se uma história nos seguintes termos:

Precisando de ajuda, discou-se este número. Pela reação da pessoa que atendeu o telefone, é errado. Não tendo como discar de novo (por exemplo, por falta de dinheiro), pede-se à pessoa que atendeu que faça a ligação em nome de quem precisa da ajuda.

A ligação volta para um ajudante do experimentador. A realização da ligação é o ato de ajuda. No contexto brasileiro, desconhecemos estudos utilizando esta técnica.

Simon (1971), entre outros, diz que a utilização do telefone em estudos sobre comportamentos de ajuda elimina o contato visual entre pessoas. Supondo que o contato visual exerça influência sobre pessoas às quais se solicita ajuda, a ausência do contato pode torná-las menos vulneráveis psicologicamente, a ponto de se comportarem como livres das pressões sociais do momento.

O presente estudo teve como objetivos: (a) verificar a freqüência de comportamento de ajuda entre habitantes de duas áreas urbanas de Brasília, por meio da técnica de número errado; (b) determinar a relação entre comportamento de ajuda e variáveis antecedentes como gênero do experimentador, gênero de quem atendeu as ligações, tipo de históriaproblema apresentada, localização do telefone contatado, tipo de residência do telefone contatado, dia da semana e horário da ligação; (c) analisar os procedimentos da técnica de número errado para produção e controle experimental de situações de ajuda.

\section{Metodologia}

\section{Seleção da População Alvo}

As regiões estudadas foram selecionadas de acordo com o tipo e a disposição das residências e com possíveis diferenças sócio-econômicas entre as populações de cada região. A amostra total de 320 residências foi selecionada aleatoriamente, a partir dos números obtidos na lista telefônica. A distribuição das amostras é apresentada na Tabela 1.

\section{Procedimentos}

A metade dos contatos foi realizada por um experimentador e a outra por uma experimentadora. Simulou-se uma situação de emergência em que se solicitava que o morador realizasse outra ligação telefônica, a fím de ajudar a pessoa (i.e., o experimentador) que estava solicitando ajuda.

4 Interessantemente, a própria disposição de participar em uma pesquisa, no caso, ser entrevistado, tem sido utilizada por Hedge e Yousif (1992) como medida não-reativa da disposição de ajudar. 
Tabela 1 - Distribuição da amostra randômica de ligações de acordo com as áreas residenciais pesquisadas.

\begin{tabular}{llc}
\hline Local & Tipo de Residência & Número de Ligações \\
\hline Centro & Apartamento & $\mathbf{9 6}$ \\
& Casa & 96 \\
Periferia & Apartamento & 64 \\
& Casa & 64 \\
\hline Total & & $\mathbf{3 2 0}$ \\
\hline
\end{tabular}

Cada contato consistiu de duas ligações, no mínimo. Na primeira, o experimentador pediu para falar com uma pessoa cujo nome havia sido preestabelecido. Informado de que ninguém na casa possuía o nome procurado, desculpava-se pelo engano e desligava-se o telefone. Uma segunda ligação para o mesmo número era realizada após aproximadamente 15 segundos. Ao receber o mesmo aviso, o experimentador argumentava que algum problema com a ligação estaria ocorrendo. O primeiro telefonema tinha sido realizado especialmente para fortalecer esta argumentação. Iniciava-se o relato da história-problema, de acordo com uma das três situações experimentais descritas a seguir.

\section{Situações experimentais}

As três situações variavam segundo o grau de relação de vizinhança futura, sendo que na primeira condição quem telefonou idenficou-se como futuro vizinho do mesmo prédio residencial do morador (ou conjunto de casas); na segunda, como futuro vizinho do mesmo bairro ou vizinhança do morador; na terceira, sem relação aparente de vizinhança, como se fosse um estranho. As três situações experimentais / história-problema foram avaliadas em um estudo piloto por ligações telefônicas realizadas em uma amostra aleatória de 50 moradores.

\section{História-problema}

A história-problema, pela qual se solicitou ajuda, foi:

Eu estou aqui no aeroporto e precisava falar urgentemente com [nome de quem se procura], porque estou de mudança para [endereço conforme situação experimental] e ele ficou de me pegar aqui, mas já se passaram duas horas do horário combinado e ele não apareceu. Já tentei ligar pra casa dele, mas ou o telefone desliga ou a ligação cai na sua casa. Talvez ele ainda esteja no trabalho ${ }^{5}$. O problema é que eu estou sem dinheiro e não vou poder mais usar este telefone pra ligar novamente, porque o pessoal da empresa aérea já está reclamando das minhas ligações. E que eu pedi para dar uma única ligação. Será que o(a) Sr.(a) não poderia telefonar para o trabalho 6 do/da [nome de quem se procura] e dizer que eu estou esperando por elelela.

5, 6 Nas ligações realizadas, nos fins de semana, dizia-se que $\mathrm{X}$ deveria estar na casa de sua mãe.

\section{Recado a ser dado pelo morador}

"O seu amigo / amiga [nome especificado por cada pesquisador] pediu para lembrar que ele / ela está esperando por você no aeroporto."

Estipulou-se um tempo máximo de 35 minutos durante o qual os telefonemas (recados) dos moradores eram aguardados.

Dentro deste procedimento padrão, os pesquisadores enfatizavam a urgência da situação, chamando a atenção do morador para o fato de que o endereço procurado era próximo do endereço do morador (mesma quadra ou bloco). Isto porque os endereços apresentados como referência da residência de quem se procurava (futuro endereço de quem pede ajuda) foram selecionados a partir do endereço do morador (decorrente da amostra de telefones) e eram sempre da mesma quadra ou bloco do morador. Foram tomadas precauções para que os endereços não fossem próximos. Se o endereço do morador fosse apartamento 210 , o da pessoa procurada não poderia ser apartamento 209 (e.g., excluíram-se vizinhos de porta) do mesmo endereço.

Quando o morador contatado possuía o mesmo nome da pessoa procurada, man tinha-se o procedimento padrão. Contava-se a história-problema como se o morador fosse a pessoa inicialmente procurada. Identificado o engano, solicitava-se a ajuda.

Os nomes das pessoas procuradas pelos experimentadores foram previamente estabelecidos, de maneira que o fornecido pelo experimentador (quem ele procurava) fosse o nome criado para a experimentadora que receberia o recado do morador (caso resolvesse ajudar). Da mesma maneira, a pessoa procurada pela experimentadora possuía o mesmo nome criado para o experimentador, que receberia o recado. Para fins de controle de quem telefonava enviando o recado e de quem recebia as ligações, perguntou-se o nome de quem lhes atendia (e.g., quem inicialmente se predispunha a ajudar) e de quem lhes telefonava (e.g., quem transmitiu o recado solicitado). Na interação com os moradores, os experimentadores procuravam demonstrar certa ansiedade ao telefonar e pedir ajuda, bem como surpresa no momento em que o endereço relatado pelo morador não era o procurado pelo experimentador.

\section{Critérios para anulação ou substituição do telefone pesquisado}

Os telefonemas eram cancelados quando uma criança atendia a primeira e a segunda ligação. Também nos casos em que a empregada atendia o telefone e nenhum outro morador era encontrado em casa. A identificação da empregada era feita perguntando à atendente se era dona do apartamento ou casa, ou se morava ou trabalhava naquela residência.

Os números telefônicos selecionados inicialmente foram substituídos nos casos em que não se encontrava um morador após dois dias de tentativas. 
Tabela 2 - Freqüências de ajuda e não ajuda em função de gênero do experimentador e tipo de história apresentada.

\begin{tabular}{|c|c|c|c|c|c|c|c|c|c|}
\hline \multirow{4}{*}{ Efetivamente prestou ajuda } & \multicolumn{4}{|l|}{ Não } & \multicolumn{4}{|c|}{ Sim } & \multirow[t]{2}{*}{ Tota } \\
\hline & \multicolumn{4}{|c|}{ Respondeu que ... } & \multicolumn{4}{|c|}{ Respondeu que ... } & \\
\hline & Não & Sim & Outra & Total & Não & Sim & Outra & Total & \\
\hline & 110 & 25 & 59 & 194 & 3 & 98 & 25 & 126 & 320 \\
\hline \multicolumn{10}{|l|}{ Gênero do experintentador } \\
\hline Feminino & 53 & 6 & 27 & 86 & 2 & 61 & 11 & 74 & 160 \\
\hline Masculino & 57 & 19 & 32 & 108 & 1 & 37 & 14 & 52 & 160 \\
\hline \multicolumn{10}{|l|}{ Tipo de historia apresentada } \\
\hline Vizinbo próximo & 42 & 8 & 17 & 67 & - & 32 & 9 & 41 & 108 \\
\hline Vizinho distante & 33 & 9 & 17 & 59 & 2 & 38 & 9 & 49 & 108 \\
\hline Estranlio & 35 & 8 & 25 & 68 & l & 28 & 7 & 36 & 104 \\
\hline
\end{tabular}

1 No caso de três pessoas, não foi possível determinar se foi a mesma ou outra pessoa que fez a ligação de ajuda.

As ligações foram feitas em dias alternados pelos experimentadores. Em um dia, o experimentador apenas fez ligações e a experimentadora somente aguardou os recados. No dia seguinte, a experimentadora fez as ligações e o experimentador aguardou os recados. Nos dias de semana, as ligações foram realizadas entre $12 \mathrm{~h} 45$ e $14 \mathrm{hl} 5$ e entre $19 \mathrm{~h}$ e $21 \mathrm{~h}$. Em fins de semana e feriados, entre $14 \mathrm{~h}$ e $16 \mathrm{~h}$ e entre $19 \mathrm{~h}$ e $21 \mathrm{~h}$. Estudos de levantamento de dados via telefone (Groves \& Kahn, 1979; Lavrakas, 1987) sugerem esses horários, porque neles há maior probabilidade de encontrar o morador em casa e de a ligação não ser atendida por empregadas. $\mathrm{O}$ estudo piloto confirmou esta tendência para o contexto local.

\section{Instrumentos}

Três linhas telefônicas foram necessárias à realização do estudo: uma para a ligação; outra para a recepção dos recados; uma terceira para servir de referência da casa de quem se procurava, caso o morador solicitasse o telefone. Cada uma das linhas ficava em diferentes cômodos isolados da casa de um dos experimentadores, de forma que eventos externos ao experimento não interferissem nos procedimentos.

\section{Resultados}

Dados de 320 ligações estavam disponíveis, sendo que $126(39,4 \%)$ pessoas retornaram as ligações, i.e., ajudaram, enquanto 194 não ajudaram. Entre os que ajudaram, 98 pessoas concordaram logo e ajudaram de fato. Outras 25 retornaram a ligação, mas somente após sugerir alternativas a quem pedia ajuda. Três moradores que inicialmente anotaram o telefone para recado disseram, posteriormente, que não ajudariam, mas minutos depois retornaram as ligações. Dentre as 194 pessoas que não ajudaram, 25 concordaram, inicialmente, em telefonar, mas não o fizeram.

$\mathrm{Na}$ Tabela 2, apresentam-se as frequiências de ajuda e falta de ajuda em função do gênero do experimentador e da história-problema apresentada. Verifica-se existir uma relação estatisticamente significativa entre gênero do experimentador e ajuda proferida, no sentido de que a experimentadora eliciou mais ajuda $\left(X_{\mathrm{df}=1}^{2}=6,336, p=0,012\right)$. A tabela também apresenta as freqüências das diferentes respostas inici- ais, tanto entre os respondentes que eventualmente ajudaram como entre os que deixaram de ajudar. Entre os respondentes que não ajudaram, a freqüência de dizer que ajudariam mas não o fizeram e de dizer logo que não ajudariam (quando de fato ajudaram) variava conforme o gênero do pesquisador. Observa-se tendência estatística no sentido de o experimentador receber desproporcionalmente mais promessas de ajuda e menos respostas francas, enquanto a experimentadora recebe desproporcionalmente menos promessas e mais respostas francas $\left(\mathrm{X}_{\mathrm{df}=2}^{2}=4,897, p=0,086\right)$.

Na Tabela 3 apresentam-se as freqüências de ajuda e falta de ajuda em função de localização do telefone (centro vs. periferia), tipo de residência (casa vs. apartamento), dia da semana e horário das ligações. Nenhuma relação estatisticamente significativa foi encontrada nessas quatro análises. No que diz respeito ao tipo de resposta inicial entre os que eventualmente ajudaram ou não, igualmente não se encontraram relações estatisticamente significativas.

A Tabela 4 apresenta os resultados de uma regressão logística com ajudar (sim vs. não) como variável-critério, e as seis variáveis apresentadas nas Tabelas 2 e 3 como antecedentes. A análise de regressão logística - técnica multivariada - permite considerar mais do que uma variável antecedente ao mesmo tempo, levando-se em conta qualquer possível relação entre as variáveis antecedentes. Em contraste à regressão múltipla, esta técnica é mais flexível, especialmente não fazendo pressuposições quanto à distribuição das variáveis antecedentes, que não precisam ser distribuídas normalmente (Tabachnick \& Fidell, 1996, p. 575ff).

Um teste do modelo completo das seis variáveis antecedentes não é estatisticamente significativo $\left(\mathrm{X}_{\mathrm{df}=8}^{2}=11,819, n\right.$ $=320, p=0,160)$, indicando que os antecedentes, como conjunto, não distinguem confiavelmente os que ajudaram dos que não ajudaram. De acordo com o critério Wald, apenas o gênero do experimentador relacionou-se de maneira significativa com a variável-critério $(\mathrm{z}=6,3778, p=0,0116)$, como determinado nos testes bivariados.

\section{Discussão}

O ponto de partida foi a maneira de estudar comportamento pró-social no contexto urbano, utilizando um método 
Tabela 3 - Frequiências de ajuda e falta de ajuda em função de localização do telefone contatado, tipo de residênciado telefone contatado, dia da semana e horário da ligação.

\begin{tabular}{|c|c|c|c|c|c|c|c|c|c|}
\hline \multirow{4}{*}{ Efetivamente prestou ajuda } & \multicolumn{4}{|l|}{ Năo } & \multicolumn{4}{|c|}{ Sim } & \multirow[t]{2}{*}{ Total } \\
\hline & \multicolumn{4}{|c|}{$\overline{\text { Respondeu que ... }}$} & \multicolumn{4}{|c|}{ Respondeu que ... } & \\
\hline & Nāo & Sim & Outra & Total & Nāo & Sim & Outra & Total & \\
\hline & 110 & 25 & 59 & 194 & 3 & 98 & 25 & 126 & 320 \\
\hline \multicolumn{10}{|c|}{$\overline{\text { Localizą̧âo do telefone contarado }}$} \\
\hline Centro & 47 & 13 & 58 & 118 & 1 & 59 & 14 & 74 & 192 \\
\hline Periferia & 63 & 12 & 1 & 66 & 2 & 39 & 11 & 52 & 128 \\
\hline \multicolumn{10}{|c|}{ Tipo de residência do relefone contatado } \\
\hline Apartamento & 62 & 11 & 30 & 103 & 2 & 43 & 12 & 57 & 160 \\
\hline Casa & 48 & 14 & 29 & 9] & 1 & 55 & 13 & 69 & 160 \\
\hline \multicolumn{10}{|l|}{$\overline{\text { Dia de semana da ligaçâo }}$} \\
\hline Dia útil & 56 & 15 & 26 & 97 & 1 & 51 & 11 & 63 & 160 \\
\hline Fim de semana & 54 & 10 & 33 & 97 & 2 & 47 & 14 & 63 & 160 \\
\hline \multicolumn{10}{|l|}{$\overline{\text { Horário da ligaçāo }}$} \\
\hline Hora do almoço & 58 & 10 & 30 & 98 & 1 & 45 & 16 & 62 & 160 \\
\hline Noite & 52 & 15 & 29 & 96 & 2 & 53 & 9 & 64 & 160 \\
\hline
\end{tabular}

Tabela 4 - Análise de regressão logística de ajudar como função de seis variáveis antecedentes.

\begin{tabular}{|c|c|c|c|c|c|c|}
\hline Variáveis & & $\boldsymbol{B}$ & $\begin{array}{l}\text { Wald test } \\
\text { (razão } z \text { ) }\end{array}$ & $d f$ & $p$ & $r$ \\
\hline Gênero do experimentador & 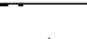 & $-0,5897$ & 6,3778 & 1 & $\overline{0,0116}$ & $-0,1010$ \\
\hline Local: centro vs. periferiá & & $-0,0839$ & 0,1251 & 1 & 0,7236 & 0,0000 \\
\hline Residência: apartamento vs. casa & 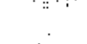 & 0,3244 & 1.9361 & $\mathbf{l}$ & 0,1641 & 0,0000 \\
\hline Dia da semana: dia útil vs. fim de semana & & $-0,0488$ & 0,0401 & $\mathbf{l}$ & 0,8414 & 0,0000 \\
\hline Horánio de ligação: almoço vs. noite & $\because$ & $-0,0464$ & 0,0396 & 1 & 0,8423 & 0,0000 \\
\hline História & & & 2,7674 & 2 & 0,2506 & 0,0000 \\
\hline Viuinho proxima & & 0,1654 & 0,2977 & 1 & 0,5853 & 0,0000 \\
\hline Vizinho distante & & 0,4703 & 2,6055 & 1 & 0,1065 & 0,0376 \\
\hline Constante & & $-0,43] 4$ & 1,7061 & 1 & 0,1910 & \\
\hline
\end{tabular}

não reativo de coleta de dados: a técnica do número errado. Uma vez que na interação social o feedback visual constituise uma variável importante e potencialmente interferente (Gaertner \& Bickman, 1971;Simon, 1971), optou-se por esta técnica, visando estudar a ausência desta retroalimentação.

Há que se constatar, inicialmente, que em comparação a estudos anteriores utilizando a técnica do número errado, o percentual de ajuda de $39,4 \%$ (variando de $32,5 \%$ a 46,25\%) pode ser considerado baixo. Gaertner e Bickman (1971), estudando comportamento de ajuda em função de características étnicas dos que telefonaram, obtiveram uma taxa geral de ajuda de $61 \%$ (variando de $49 \%$ a $73 \%$ ) na cidade de Nova York em 1969. Simon (1971), em um estudo de comportamento em função do gênero do experimentador e do respondente, obteve taxa geral de ajuda de $71 \%$ (variando entre $63 \%$ e $79 \%$ ) em Southampton, NY, uma cidade pequena de Long Island. Em ambos os estudos, a história-problema-foi a mesma: pediu-se contatar um posto de serviço após problema com carro. Goodman e Gareis (1993) obtiveram taxa geral de ajuda de $62 \%$ (variando de $45 \%$ a $75 \%$ ) na área metropolitana de Boston, em 1989, sendo a história-problema um pedido de aviso de que o experimentador chegaria atrasado ao emprego.

Quanto aos resultados do contexto cultural norte-americano, a diferença entre as taxas gerais de ajuda no estudo de
Gaertner e Bickman e de Goodman e Gareis, ambos em cidades grandes, e de Simon em uma cidade pequena, reforça críticas existentes sobre os habitantes de áreas urbanas, no que diz respeito à frieza e à distância entre pessoas, podendo evidenciar deficiências no que Milgram (1970) denomina de responsabilidade social ou envolvimento moral. Apesar de o fato da história-problema ser diferente no estudo de Gaertner e Bickman (carro quebrado) e de Goodman e Gareis (atraso no emprego), bem como a diferença de mais de vinte anos na realização dos estudos, destaca-se o fato que as taxas gerais de ajuda são quase iguais.

Ao observar a diferença substancial entre os dados de três cidades norte-americanas e os da cidade de Brasília na taxa geral de ajuda, devem ser considerados os diferentes contextos culturais dos estudos. Devido às diferenças culturais, usou-se uma história-problema diferente, que levou em conta as diferenças da telefonia nos dois países. Antes de atribuir a taxa baixa de ajuda simplesmente a características de Brasília, seria necessário repetir estudos desta natureza em outras cidades do Brasil.

Para explicar a taxa da ajuda obtida, vale analisar os comentários de relutância em ajudar. Uma análise das frequiências apresentadas na Tabela 2 indica que a maioria das pessoas que, inicialmente, se dispõe a ajudar realmente ajuda. Porém, um grupo de moradores que ajudou foi mais relu- 
tante, ajudando após argumentar sobre alternativas à situação apresentada. Alguns moradores sugeriam que ligassem de outra empresa aérea, ou que os pesquisadores tentassem novamente, ou que pedissem a outra pessoa que estivesse no aeroporto, ou ligassem a cobrar de telefone público. Ocorreram casos em que o morador simplesmente sugeriu nova desculpa para o pesquisador apresentar à 'pessoa da empresa aérea' ("diz que você ligou, mas a linha caiu"). A relutância pode ter ocorrido porque os moradores pensaram tratarse de "trote", mas pode indicar um aspecto característico do comportamento de pessoas que tendem a se esquivar da tarefa solicitada (ajuda).

$O$ fato de que diferenças significativas na probabilidade de ajuda podem ser atribuídas apenas ao gênero de quem pede ajuda é respaldado por Simon (1971). O autor sugere que a situação experimental para a qual se pede ajuda pode favorecer solicitantes femininas: um carro avariado. Na medida em que as mulheres são percebidas como menos conhecedoras de mecânica do que os homens, elas podem elicitar um maior número de comportamentos de ajuda. No presente estudo, procurou-se eliminar este tipo de variável confundível, supondo-se que as situações experimentais escolhidas não favorecem por si sós a probabilidade de ajuda a um ou outro gênero. Além do mais, a ajuda solicitada não apresentou características ambíguas, nem elevado custo comportamental para a pessoa contatada. Aspectos que por si mesmos poderiam diminuir a probabilidade de se receber ajuda (Clark \& Word, 1974). Em termos de vulnerabilidade, ressalta-se que em duas situações experimentais quem pedia ajuda poderia vir a ser um vizinho do morador. Apesar disto, os moradores parecem não ter se preocupado com a probabilidade de quem pedia ajuda poder ligar para saber, posteriormente, se o recado fora dado.

Goodman e Gareis (1993) observaram que diferenças de status podem exercer influência sobre comportamentos de ajuda. No presente estudo, era esperado um resultado semelhante, uma vez que diferentes níveis de renda podem ser presumidos entre os moradores das duas áreas pesquisadas. Na medida em que os dados encontrados não apontam uma diferença na disposição de ajudar entre moradores do centro da cidade \{status social mais semelhante com quem viaja de avião) e da periferia (status social potencialmente mais baixo do que viajante de avião), este aspecto terá de ser revisto. A variável 'relações futuras de vizinhança' tampouco mostrou-se relevante, fortalecendo o argumento de que habitantes urbanos apresentam, de maneira geral, certos padrões 'negativos' de comportamento social. Vale ressaltar que, em determinadas situações, o grau de disposição para ajuda entre habitantes dessas duas regiões urbanas pode ser notavelmente diferente (Silva \& Günther, 1996). São necessários mais estudos com maior variação e maior número de situações de ajuda entre residentes desses locais.

A falta de relacionamento entre as variáveis 'tipo de residência' e comportamento de ajuda (vide Tabela 2) é notável diante de resultados de estudos atitudinais anteriores sobre senso de comunidade. Esses dados têm sugerido que moradores de apartamentos, habitantes de uma das regiões estudadas, apresentam sentimento de identificação com suas moradias (quadras, blocos), mas mostram menos disposição verbal para ajudar vizinhos mais próximos, do mesmo bloco, do que vizinhos da mesma quadra (Günther, Flores \& Silva, 1992). Possivelmente, moradores de casas, mais do que de apartamentos, percebem-se vulneráveis a certas 'inconveniências sociais' devido ao limite mais tênue entre a casa e a rua. Assim, situações que implicam em uma potencial vulnerabilidade podem resultar em diferenças no nível de ajuda, como pedir para usar o telefone ou aplicar um questionário, porque implica permitir que o solicitante penetre na casa ou no apartamento. No presente caso, porém, o pedido em si não implicava situação de vulnerabilidade, a menos que o não prestar ajuda a um futuro vizinho fosse assim interpretado. Se a vulnerabilidade está relacionada ao tipo de residência é algo a se saber.

Segundo Fischer (1975), moradores de diferentes regiões da mesma área urbana podem apresentar diferenças comportamentais devido a características específicas de tais regiões (e. g., aspectos culturais); comportamentos semelhantes podem ocorrer em função dessas características. Os resultados do presente estudo não permitem diferenciação significativa no que diz respeito ao comportamento de ajuda entre moradores das duas regiões estudadas, seja por alguma característica semelhante entre os habitantes, ou, como sugere Milgram (1970), por adaptações semelhantes a situações específicas. Eram esperadas diferenças comportamentais, vez que as regiões estudadas apresentam populações de nível sócio-econômico diferenciado (área central com maior poder econômico). Por outro lado, a pequena distância entre as duas áreas (menos que $5 \mathrm{~km}$ ) e o constante fluxo de habitantes da região periférica para o centro podem ter influenciado, como apontado por Fischer. Estudos subseqüentes poderiam investigar habitantes de regiões com menor intercâmbio de habitantes.

\section{Delineamento experimental por meio de telefone}

Uma das vantagens da metodológica de surveys por telefone, apontada por Groves e Kahn (1979) e Lavrakas (1987), o controle de aspectos visuais da interação pesquisador respondente também é relevante para estudos do comportamentos de ajuda. As características de demanda da tarefa constituem ameaça básica à validade interna de pesquisas sobre comportamentos socialmente desejáveis, como a ajuda. Pesquisas envolvendo o telefone como meio de contato entre pesquisador e pesquisado ajudam a reduzir o problema.

A maneira de selecionar os números telefônicos merece atenção especial. Existem duas formas básicas para se obter uma amostra randômica. A seleção pode ser realizada com base na lista telefônica que cobre a população-alvo, ou podem ser criadas seqüências numéricas randômicas levando em conta os prefixos dos telefones da região de interesse. A maneira pela qual serão selecionados os números dependerá do que se quiser controlar.

Neste estudo, o interesse em investigar casas e apartamentos residenciais fez com que a seleção fosse realizada 
com base em lista telefônica de endereços dos dois tipos de habitação. Determinadas as regiões da cidade, realizou-se uma seleção randômica entre os endereços. Identificados os endereços, os telefones destas residências foram procurados. Na eventualidade de não constar um telefone em um determinado endereço, substituiu-se pelo endereço vizinho. E importante dar atenção à substituição de endereços. Recomenda-se não somente estabelecer uma regra de substituição para os casos de não atendimento, mas realizar seleção prévia de endereços e telefones conforme esta regra, antes de começar a coleta de dados.

Quanto ao setting onde são realizadas as ligações, deve-se observar o número de linhas telefônicas e pesquisadores necessários, além do isolamento acústico, para que eventos externos não prejudiquem o estudo. Neste estudo, considerouse, inicialmente, o uso de duas linhas: uma para realizar ligações, outra para receber os recados dos moradores. Antecipando a possibilidade dos contatados pedirem o telefone da casa da pessoa que deveria buscar quem pedia ajuda, foi utilizada mais uma linha. Embora na nossa avaliação inicial isto não fosse necessário, de fato aconteceu. Um dos contatados pediu o telefone da pessoa procurada, alegando que ele poderia tentar ligar para o morador, uma vez que o problema poderia ser com a linha do aeroporto. Forneceu-se o número dessa terceira linha telefônica, explicando tratar-se do telefone de um outro amigo, não o de quem era inicialmente procurado. Vale lembrar que a solicitação era telefonar para o trabalho (casa da mãe, em fins de semana), em vez de fazê-lo para a casa de quem deveria ter buscado quem pedia ajuda, justamente porque os prefixos das linhas do contatado e do pesquisador poderiam ser distintos a ponto de identificar partes diferentes da cidade. A diferença poderia despertar suspeitas nas condições experimentais, quando se estava ligando para o vizinho de bloco ou de quadra do contatado. Deve-se lembrar que muitas pessoas possuem aparelhos de identificação de chamadas. Assim, é importante que o prefixo do telefone utilizado não interfira na consistência da história-problema.

A realização de um ou mais estudos pilotos é importante, vez que verifica a eficácia da preparação do setting e permite o treinamento dos que realizam os contatos por telefone. Dever-se-á tentar identificar o maior número possível de reações dos sujeitos e testar a adequação metodológica frente a possíveis interferências. A história-problema a ser contada aos moradores é consistente ou existe algum 'furo' ao qual alguém reage? Os experimentadores devem ser treinados para realizar o mesmo procedimento padrão frente a situações semelhantes. Sugere-se treinamento conjunto, de forma que um experimentador possa observar o desempenho do outro e ouvir a interação entre ele e o sujeito. Dessa maneira, os experimentadores podem discutir seus desempenhos e estabelecer, juntos, soluções padronizadas. Mereceu muita atenção neste estudo o fato de que empregadas atendem telefone. Sendo objetivo investigar o comportamento do morador, estabeleceu-se um procedimento para determinar o status do atendente à ligação. Perguntava-se sempre "Você também mora aí? Queria falar com um dos moradores". Ainda no estudo piloto, procurou-se identificar em que horários seria menos provável uma empregada atender a ligação. Verificou-se que seria no horário de almoço e após as 19h45. A identificação de moradores ansiosos, mal-humorados, etc, ocorreu com certa facilidade, mas de acordo com o objetivo específico do estudo, não foi motivo para interrupção da ligação. Embora esse dado não tenha sido sistematizado, ficou a impressão de que pessoas ansiosas retornavam as ligações mais rapidamente, enquanto que as mal-humoradas sequer esperavam o fim do relato, desligando. Vale lembrar que se ligou duas vezes para cada número, o que implicou na possibilidade de um mesmo morador 'mal-humorado' atender as duas ligações.

A existência de aparelhos de identificação de chamadas deve ser considerada no planejamento de estudos com telefone, porque permite que o morador perceba que o número de origem da chamada não corresponde ao local relatado na história-problema (no presente estudo, o aeroporto). Ocorreu neste estudo que um morador, imediatamente após concordar em ajudar, retornou a ligação para o número a partir do qual o experimentador realizou a chamada. Porém, o pesquisador também tinha à disposição um aparelho de identificação de chamadas, permitindo que outra pessoa que não o pesquisador atendesse a ligação de quem desconfiasse de um trote. Não somente o problema foi solucionado - o morador desligou sem falar nada - mas também retornou a ligação corretamente, dando o recado solicitado.

Experimentos sociais com encenação de histórias são especialmente sensíveis quanto ao desempenho dos atores, i.e., experimentadores. No caso de estudos com telefone, a realização de muitas ligações em um mesmo dia pode prejudicar o desempenho. O procedimento inicial deste estudo previa três ligações diárias: duas pela manhã e uma à noite; no dia seguinte, uma pela manhã e duas à noite. Verificou-se que o desempenho na segunda ligação do turno poderia sofrer interferência da primeira pelas expectativas que criava: quando o morador da primeira ligação não ajudava, mostrava irritação ou alguma forma de resistência em ajudar. Optou-se por realizar apenas uma ligação por turno, evitandose que uma ligação afetasse imediatamente a seguinte. Vale mencionar que embora o problema tenha sido notado já no estudo piloto, somente com o aumento no número de ligações o fato mostrou-se relevante e a 'expectativa' recebeu a devida atenção. Mesmo após redução do número de ligações por dia, os dois experimentadores relataram que a tarefa era cansativa pela atenção que a encenação exigia.

\section{Conclusão}

Comparado com resultados obtidos em estudos no exterior, o nível de ajuda encontrado entre os moradores de Brasília pode ser considerado baixo. Antes de tirar conclusões quanto ao comportamento pró-social específico do brasiliense, é necessário repetir esses estudos em outras localidades do Brasil e utilizar outras metodologias (Silva, Günther, Lara, Cunha \& Almeida, 1998).

Os resultados indicam que, no procedimento do estudo, a chance de uma mulher receber ajuda é significativamente 
maior que a de um homem, enquanto que tipo de residência (casa vs. apartamento) ou local de moradia (centro vs. periferia) não parecem influenciar o nível de ajuda.

As possibilidades metodológicas do telefone mostraramse vantajosas para estudos sociais experimentais, especialmente porque muitos detalhes podem ser modificados e controlados adicionalmente, dependendo dos objetivos do estudo.

\section{Referências}

Abreu, M. (1997, 20 de agosto). Quando o inimigo mora ao lado. Correio Braziliense [on-line], secção Cidade. (Disponível: http:/ Avww.correioweb.com.br)

Amato, P.R. (1983a). The helpfulness of urbanites and small town dwellers: A test between two broad theoretical positions. Australian Journal of Psychology, 35, 233-243.

Amato, P.R. (1983b). Helping behavior in urban and rural environments: Field studies based on a taxonomic organization of helping episodes. Journal of Personality and Social Psychology, $45,571-586$.

Amato, P.R. (1983c). Urban-rural differences in helping friends and family members. Social Psychology Quarterly, 56, 249262.

Boise, K. \& Goldman, M. (1981). Helping behavior as affected by type of request and identity of caller. Journal of Social Psychology, 115, 95-101.

Clark III, R.D. \& Word, L.E. (1974). Where is the apathetic bystander? Situational characteristics of the emergency. Journal of Personality and Social Psychology, 29, 279-287.

Cunningham, S. (1984). Genovese: 20 years later, few heed a stranger's cries. Social Action and the Law, 10(1), 24-25.

Darley, J. \&Latané, B. (1968). Bystander intervention in emergencies: diffusion of responsibility. Journal of Personality and Social Psychology, 8, 377- 383.

Eagly, A.H. \& Crowley, M. (1986). Gender and helping behavior: A meta-analytic review of the social psychological literature. Psychological Bulletin, 100, 283-308.

Eisenberg, N. (1991). Meta-analytic contributions to the literature on prosocial behavior. Personality and Social Psychology Bulletin, 17, 273-282.

Fischer, C. (1975). Toward a sub-cultural theory of urbanism. American Journal of Sociology, 80, 1319- 1341.

Franklin, B.J. (1974). Victim characteristics and helping behavior in a rural southern setting. Journal of Social Psychology, 93, 93-100.

Gaertner, S. \& Bickman, L. (1971). Effects of race on the elicitation of helping behavior: The wrong number technique. Journal of Personality and Social Psychology, 20, 218- 222.

Goldman, M., Broil, R. \& Carrill, R. (1983). Requests for help and prosocial behavior. Journal of Social Psychology, 119, 55-59.

Goodman, M.D. \& Gareis, C.K. (1993) .The influence of status on decision to help. The Journal of Social Psychology, 133, 2331.

Groves, R.M. \& Kahn, R.L. (1979). Survey by telephone: A national comparison with personal interviews. New York: Academic Press.
Günther, H., Flores. E.P. \& Silva A.V. (1992). Senso de comunidade entre habitantes das superquadras do Plano Piloto [Resumo]. Em Sociedade Brasileira de Psicologia (Org.), Resumos de comunicações científicas, XXII Reunião Anual de Psicologia (p. 190). Ribeirão Preto: SBP.

Harris, M.B. \& Klingbeil, D.R. (1976). The effects if ethnicity of subject and accent and dependency of confederate on aggressiveness and altruism. Journal of Social Psychology, 98, 4753.

Hedge, A. \& Yousif, Y.H. (1992). Effects of urban size, urgency, and cost on helpfulness: A cross-cultural comparison between the United Kingdom and the Sudan. Journal of Cross-Cultural Psychology, 23, 107-105.

House, J.S. \& Wolf, S. (1978). Effects of urban residence on interpersonal trust and helping behavior. Journal of Personality and Social Psychology, 36, 1029-1043.

Howard, W. \& Crano, W.D. (1974). Effects of sex, conversation, location, and size of observer group on bystander intervention in a high risk situation. Sociometry, 37, 491-507.

Kammann, R., Thomson, R. \& Irwin, R. (1979). Unhelpful behavior in the street: City size or immediate pedestrian density? Environment and Behavior, 11, 245-250.

Korte, C. (1980). Urban-nonurban differences in social behavior and social psychological models of urban impact. Journal of Social Issues, 36, 29-51.

Latané, B. \& Darley, J.M. (1970). The unresponsive bystander: Why doesn 't he help ? New York, Prentice Hall.

Lavrakas, P.J. (1987). Telephone survey methods. Sampling, selection end supervision. Newbury Park, CA: Sage.

Lay, C, Allen, M. \& Kassirer, A. (1974). The responsive bystander in emergencies: Some preliminary data. Canadian Psychologist, 75,220-227.

Lerner, R.M., Solomon, H. \& Brody, S. (1971). Helping behavior at a busstop. Psychological Reports, 28, 200.

Mallozzi, J., McDermott, V. \& Kayson, W.A. (1990). Effects of sex, type of dress, and location on altruistic behavior. Psychological Reports, 67, 1103-1106.

Milgram, S. (1970). The experience of living in cities: Adaptations to urban overload create characteristc qualities of city life that can be measured. Science, 167, 1461-1468.

Mishra, P.K. \& Das, B.K. (1983). Group size and helping behavior: A comparative review. Perspectives in Psychological Research, 6, 60-64.

Rotton, J. (1977). Sex, residential location, and altruism. Psychological Reports, 40, 102.

Shaffer, D.R. \& Grazziano, W.B. (1980). Effects of victim's race and organizational affiliation on receiving help from Blacks and Whites. Personality and Social Psychology Bulletin, 6,366-372.

Shaw, J.I., Borough, H.W. \& Fink, M.I. (1994). Perceived sexual orientation and helping behavior by males and females: The wrong number technique. Journal of Psychology and Human Sexuality, 6, 73-81.

Silva, A.V. \& Giinther, H. (1996). Comportamentos de ajuda entre passageiros de ônibus urbano [Resumo]. Em Sociedade Brasileira de Psicologia (Org.), Resumos de comunicações científicas, XXVI Reunião Anual de Psicologia (p. 188). Ribeirão Preto: SBP. 
Silva, A.V. Günther, H,, Lara, A.A., Cunha, L.F. \& Almeida, V.J.S. (1998). Técnica da Carta-Perdida como instrumento de pesquisa social: um estudo sobre preconceito e ajuda. Psicologia: Reflexão e Crítica, 11, 117-134.

Simon, W.E. (1971). Helping behavior in the absence of visual contact as a function of sex of asking for help and sex of person being askeng for help. Psychological Reports, 28, 609-610.

Solomon, L.Z., Solomon, H. \& Maiorca, J. (1982). The effects of bystander's anonymity, situational ambiguity, and victim's status on helping. Journal of Social Psychology, 117, 285-294.

Steblay, N.M. (1987). Helping behavior in rural and urban environments: A meta-analysis. Psychological Bulletin, 102, 346356.
Tabachnick, B.G. \& Fidell, L.S. (1996). Using multivariate statistics (3' ed.). New York: Harper Collins.

West, S.G.; Whitney, G. \& Shnedler (1975). Helping a motorist in distress: The effects of sex, race, and neighborhood. Journal of Personality and Social Psychology, 31, 691-698.

Wirth, L. (1938). Urbanism as a way of life. American Journal of Sociology, 44, 1-24.

Wunderlich, E. \& Willis, F.N. (1977). The youth of victims as a factor affecting the probability of receiving aid. Journal of Psychology, 97, 93-94. 